The Chittagong Univ. J. B. Sci., Vol. 5(1 \&2):149-154, 2010.

SHORT COMMUNICATION

\title{
ANTIBACTERIAL AND ANTIFUNGAL ACTIVITY OF ETHANOL EXTRACT OF CURCUMA CASIEA
}

Curcuma casiea (Black Turmeric) is a kind of turmeric with bluish-black rhizome, famous for its unique medicinal properties. It is a perennial herb, belonging to Zingiberaceae (Ginger) family, native to North-East and Central India. The leaves have a deep violet-red patch which runs through the length of the lamina. Usually, the upper side of the leaf is rough and velvety, but this character may vary. Flowering bracts are green with a rustic tinge. Flower petals may be deep pink or red in color. The inside of the rhizome is deep-blue or bluish-black in color. The rhizome is bitter, hot taste with pungent smell. The name 'black turmeric' holds due to the presence of cells related to black color in the rhizome. The rhizome slightly resembles the light-grey rhizome of Curcuma aeruginosa. Scientific researches on the volatile rhizomes oil of Curcuma casiea resulted in the identification of 30 components, representing $97.48 \%$ of the oil, with camphor (28.3\%), ar-turmerone (12.3\%), (Z)--ocimene (8.2\%), ar-curcumene $(6.8 \%), 1,8$-cineole $(5.3 \%)$, -elemene (4.8\%), borneol $(4.4 \%)$, bornyl acetate $(3.3 \%)$ and -curcumene $(2.82 \%)$ as the major constituents. Curcuma casiea was claimed to be useful in treating piles, leprosy, bronchitis, asthma, cancer, epilepsy, fever, wounds, impotency, fertility, menstrual disorders, tooth ache, vomiting etc.

Curcuma casiea is still widely used as a medicinal plant around the world. Microorganisms have developed resistance to many antibiotics and this has created immense problem in the treatment of infectious diseases. This situation forced scientists to search new antimicrobials. Secondary metabolites proved to be the most important group of compounds that showed wide range of antifungal and antibacterial activity (Ahmed et al. 2002, Aureli 1992, Rahman et al. 1999). So, there are continuing needs for new antibacterial and antifungal agents since none of the available drugs are free from adverse effects and limitation. Considering the value of plants and other natural products as agents for infectious disease treatment, an attempt was made by present study to evaluate the effect of ethanol extract of Curcuma casizea as antimicrobial agent. 
Curcuma casiea rhizomes were collected from Shilak dak Rangamati, Chittagong, Bangladesh. Rhizomes were cut into small pieces (1-2cm), air dried, powdered mechanically and extracted with 90\% ethanol. The extract was filtered \& concentrated to near dryness under reduced pressure and low temperature $\left(40-50^{\circ} \mathrm{C}\right)$ with the help of the rotary vacuum evaporator. A measured amount of the test sample was dissolved in definite volume of ethanol to give solution of known concentration $(2 \mathrm{mg} / \mathrm{ml})$.

The acute toxicity test aims at establishing the therapeutic index, i.e. the ratio between the pharmacologically effective dose and the lethal dose on the same strain and species. The greater the index, the safer is the compound. Because of species variation, several species of animals are used to determine the LD50 or median lethal dose. In our study, the LD50 of the extract of Circuma casiea is $80 \mathrm{mg} / \mathrm{kg}$ I.V.in mice.The doses of $10 \mathrm{mg} / \mathrm{kg}, 20 \mathrm{mg} / \mathrm{kg} \& 30 \mathrm{mg} / \mathrm{kg}$ were used to see the antineoplastic activity of Circuma caesia.

To find out the effect of Circuma casiea extract (whole rizome) on the morality of brine shrimp nouplii median lethal concentration of brine shrimp (LC50) was measured and it was found to be $7.20 \mu \mathrm{g} / \mathrm{ml}$.

Bacterial test organisms were Bacillus cereus BTTC 19, Bacillus subtilis BTCC 17, B.megaterium BTCC18, Shigella dysenteries AE 14396, Shigella sonnei ICDDR'B Salmonella typhi AE 14612, Staphylococcus aureus ATTC 6538, Escherichia coli. ATCC 25922, Vibriocholearae (INABA-ET) AE 14748, Pseudomonas sp. The bacterial strains were collected from the Institution of Nutrition and Food Science, Dhaka University and ICDDR'B, Dhaka. Fungal test organisms were Aternaria alternata (Fr.) Keissler, Botryodiplodia theobromae Pat. Colletotichum corchori Ikata (Yoshida), Curvularia lunata (Wakker) Boedjin, Fusarium equiseti (Corda) Sac and Macrophomina phaseolina (Maulbi) Ashby. Fungal strains were collected from Dept. of Microbiology, Chittagong University.

The in vitro antibacterial activity of the extract was done following the agar cup plate method (Rao \& Nigam 1970) and nutrient agar was used as basal medium for bacterial growth. Hundred $\mathrm{ml}$ of the extract $(2 \mathrm{mg} / \mathrm{ml})$ was poured into the agar cup. The plates were kept in the freeze for diffusion and then incubated at $37^{\circ} \mathrm{C}$ for 24 to 48 hours. The activity was expressed in terms of the 


\section{ANTIBACTERIAL AND ANTIFUNGAL ACTIVITY OF C. CASIEA}

diameter of zone of inhibition in $\mathrm{mm}$. All the results were compared with standard antibiotic Ampicillin $(20 \mu \mathrm{g} / \mathrm{disc})$.

The in vitro antifungal activity of the extract was determined following the poisoned food technique of Grover and Moore (1962) using potato dextrose agar medium. The extract was dissolved in ethanol \& then mixed with sterilized PDA to obtain a final concentration of $2 \mathrm{mg} / \mathrm{ml}$. Nystatin was used as standard antifungal antibiotic $(100 \mu \mathrm{g} / \mathrm{ml})$ for comparison of results under identical conditions. The inoculated plates were incubated at $25^{0} \pm 1^{0} \mathrm{C}$ for 3-5 days. The percentage inhibition of radial mycelial growth of test fungi was calculated as follows :

$$
I=\frac{(C-T)}{C} \times 100
$$

Where, I =Percent of inhibition,

$\mathrm{C}=$ Diameter of fungal colony in the control,

$\mathrm{T}=$ Diameter of fungal colony in the treated.

The antibacterial activity of alcoholic extract of Curcuma casiea was determined and the result is presented in the table-1. It was found that the degree of susceptibility varied depending on the species. The extract showed broad spectrum antibacterial activity against all the test organisms except Shigella dysenteriae and Shgella sonnei. 
CHOWDHURY ET AL.

TABLE 1: ANTIBACTERIAL ACTIVITY OF ETHANOL EXTRACT OF CURCUMA CASIEA.

\begin{tabular}{|c|c|c|c|c|c|c|c|c|c|c|}
\hline \multicolumn{11}{|c|}{ Zone of inhibition in of Curcuma casiea in mm. } \\
\hline \multicolumn{11}{|c|}{ Bacterial test organisms } \\
\hline 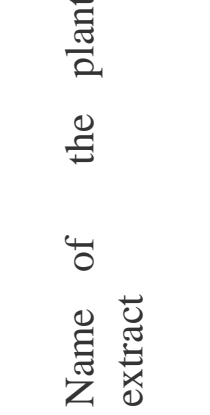 & 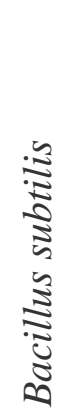 & 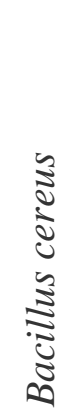 & 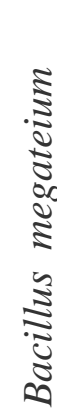 & 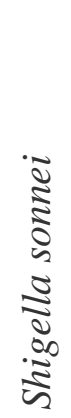 & 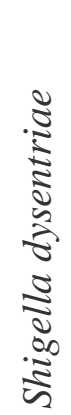 & 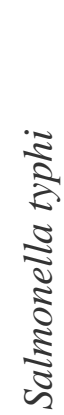 & $\begin{array}{c}\frac{1}{2} \\
\frac{1}{0} \\
\frac{0}{0} \\
\frac{0}{0} \\
0\end{array}$ & 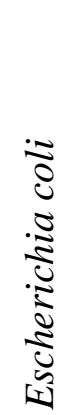 & $\begin{array}{l}\dot{0} \\
5 \\
0 \\
0 \\
\vdots \\
\vdots \\
0 \\
0 \\
0 \\
0 \\
0\end{array}$ & 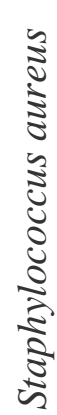 \\
\hline $\begin{array}{l}\text { Curcuma } \\
\text { casiea }\end{array}$ & 17 & 20 & 17 & - & - & 21 & 27 & 23 & 12 & 27 \\
\hline *Ampicillin & 25 & 22 & 22 & 20 & 35 & 30 & 30 & 16 & 13 & - \\
\hline
\end{tabular}

(-) Indicates no zone of inhibition * * Standard antibiotic

However the highest inhibition was recorded with Vibrio cholera and Staphylococcus aureus $(27 \mathrm{~mm})$. Table -2 represents the antifungal activity of alcoholic extract of $C$. casiea. The rhizome extract of $C$. casiea showed wide range of antifungal activity with marked radial mycelial growth inhibition against all the phytopathogens tested. However the highest antifungal activity was recorded against Macrophomina phaseolina $(77.44 \%)$. 
ANTIBACTERIAL AND ANTIFUNGAL ACTIVITY OF C. CASIEA

TABLE 2: ANTIFUNGAL ACTIVITY OF ETHANOL EXTRACT OF CURCUMA CASIEA.

\begin{tabular}{|c|c|c|c|c|c|c|}
\hline \multicolumn{7}{|c|}{ Percent radial mycelial growth inhibition } \\
\hline 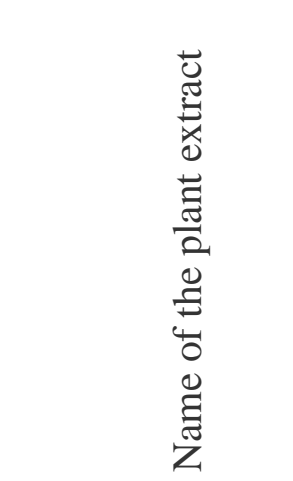 & $\begin{array}{c}0 \\
0 \\
0 \\
0 \\
0 \\
0 \\
0 \\
0 \\
0 \\
0 \\
0 \\
0 \\
0 \\
0 \\
0 \\
0\end{array}$ & 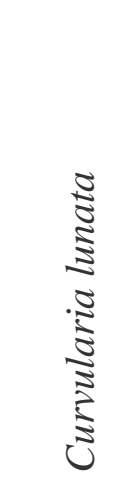 & 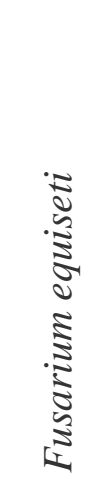 & 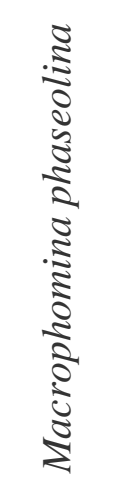 & 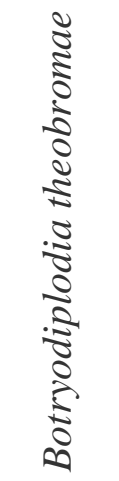 & 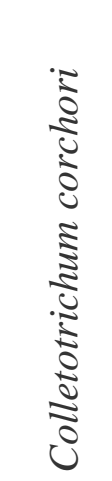 \\
\hline Curcuma caseia & 60.20 & 67.18 & 50.26 & 72.44 & 56.52 & 64.30 \\
\hline *Nystatin & 55.55 & 72.41 & 45.79 & 70.78 & 82.35 & 42.00 \\
\hline
\end{tabular}

Medicinal plants are an important source of new compound for the discovery and development of chemotherapeutic agents. So $C$. casiea used in traditional and folk medicine may serve as a potential source of natural antibacterial and antifungal agent.

\section{REFERENCES}

AHMED, A.M.A., RAHMAN, M.S., AND ANWAR,M.N.1999.Antimicrobial activity of extracts and crude alkaloids of Polyalthia longifolia (Sonn.) Chittagong Univ. J. Sciences.23 (1):53-56

AURELI, P., COSTANTINI, A. AND ZOLEA, S.1992.Antimicribial activity of some plant essential oil against Listeria monocytogenes. J. Food Science. 55:344-348 
CHOWDHURY ET AL.

GOVER R.K AND MOORE J.D.1962. Toximetric studies of fungicides against brown rot organisms Sclerotina flucticola and S. laxa. Phytopathol. 52:876-880

RAHMAN, M.S., BEGUM, J., CHOWDHURY, J.U. AND ANWAR, M.N.1998. Antimicrobial activity of Holarrhena antidysenterica stem bark. Bangladesh J.Microbiol.16(2):101-105

RAO, N.B.V. AND NIGAM, S.S. 1970. The in vitro antimicrobial efficiency of essential oils. Indian J. Med. Res. 58: 627-633.

ZULKARNAIN CHOWDHURY, MOHAMMAD SAYEDUL ISLAM, MOHAMMAD RAZUANUL HOQUE, A.M.MASUDUL AZAD CHOWDHURY ${ }^{1}$, ROBIUL HASAN BHUIYAN AND MOHAMMAD ALAUDDIN*.

Department of Biochemistry and Molecular Biology, University of Chittagong, Chittagong 4331, Bangladesh.

${ }^{1}$ Department of Genetic Engineering and Biotechnology, University of Chittagong, Chittagong 4331, Bangladesh.

* Corresponding author

Manuscript received on 24. 5. 2010; Accepted on 29.9.11

The Chittagong University Journal of Biological Sciences, Vol. 5 (1 \& 2). Page No:149-154 